\title{
The morphology of Marinesco bodies (paranucleolar corpuscles) in the melanin-pigmented nuclei of the brain-stem
}

\author{
P. YUEN AND D. W. BAXTER \\ From the College of Medicine, University of Saskatchewan, Canada
}

In 1902 Marinesco described the presence of spherical acidophilic bodies in the nucleoplasm of the cells of the human nucleus substantia nigra and the nucleus locus caeruleus. He wrote: 'The number of these corpuscles vary from one to six, and generally there are one, two or often three. When they are numerous we find them heaped in groups in the nuclear sap, and the position they occupy with regard to the nucleolus is equally variable. Sometimes they are situated in the neighbourhood of the latter, sometimes they are set aside and can even reside at the two poles of the nucleus. As to their relative sizes, they are seldom larger than the nucleolus, sometimes they can be nearly equal, but generally they are smaller than the latter, especially when they are numerous. The diameter of these paranucleolar corpuscles can reach $7 \mu$ '.

'The size of these corpuscles does not appear to be related with age, for the biggest diameter which we found was in a 30-year-old man. Generally speaking, they are more numerous in adults and old people than young persons. In the latter, in fact, they are rarely found and are absent in children.'

Marinesco elaborated further on the staining properties of these paranucleolar corpuscles in 1909. Remarkably little attention has been paid to them, at least in the British literature, since that time. Greenfield (1958) and Lipkin (1959) refer briefly to them, and Wolf and Orton (1932) have described similar intranuclear inclusions in unpigmented cells of the central nervous system in diverse disease states. This paucity of interest is all the more surprising in view of the widespread interest in cytoplasmic inclusions in the cells of the substantia nigra and locus caeruleus in paralysis agitans and other extrapyramidal syndromes.

The aim of the present study was to determine the frequency with which Marinesco bodies could be found and whether their presence could be correlated with specific or general types of disease or with the age of the patient. We also sought to determine further the histochemical properties of the inclusions and any relationship which the inclusions might have to melanin pigmentation.

\section{MATERIAL AND METHODS}

Cross sections were prepared thrcugh the brain-stems of 160 randomly chosen cadavers at the levels of the nucleus substantia nigra and the nucleus locus caeruleus. The brain-stems had been fixed in $10 \%$ formalin for 10 to 20 days and the blocks were embedded in paraffin. The histological sections were $6 \mu$ thick and stained with haematoxylin and eosin.

Each cross section containing cells of the substantia nigra was scanned for the presence of Marinesco bodies. In most cases only the 350 to 450 cells which form the substantia nigra on one side of the midbrain were scanned in detail. If such cells were found they were noted as being many (more than 10 cells), few (six to 10 cells), rare (one to five cells), or absent. If absent, the opposite substantia nigra was scanned in similar detail and if any Marinesco bodies were found the classification was changed from absent to rare. Serial sections were not examined in those instances in which Marinesco bodies were not demonstrated in a single cross section. Further notes were made concerning the location of the cells containing Marinesco bodies within the nucleus substantia nigra, and the presence of any nucleolar, nuclear, or cytoplasmic peculiarities which these cells might possess. Attempts were then made to correlate these observations with the age of the patient, the cause of death, and the duration of the terminal illness (Tables I and II).

Similar observations were made on the cells of the nucleus locus caeruleus in a few cases. In view of the small number of cells present in a single cross section it was necessary to study serial sections in most instances.

The following histological techniques were used to examine in further detail the staining properties of the Marinesco bodies: The Feulgen reaction for D.N.A., toluidine blue and gallocyanin stains for nucleic acids, Danielli's coupled tetrazonium reaction for aromatic alpha-amino acids, fast-green stain for histones, the periodic-acid-Schiff reaction for muco- and glycoproteins, Sudan IV and Sudan black for lipids, Von Kossa's stain for calcium, Gomori's stain for iron, Fontana silver stain, Mallory's trichome and Masson's 
trichome stains, Heidenhain stain for myelin, Nissl cresyl violet stain, and Van Gieson's stain.

\section{OBSERVATIONS}

Marinesco bodies could be demonstrated within some cells of the nucleus substantia nigra in the majority of patients over 21 years of age (Table I). Such cells were rare before the age of 30 years but could be found with relative ease in most older patients. There were, however, occasional cases in all age groups in which Marinesco bodies could not be demonstrated. It seems possible that if serial sections of the substantia nigra had been studied in such cases Marinesco bodies would have been demonstrated at least in some of these.

There was no correlation between the presence of Marinesco bodies and the type of terminal illness. They were found as frequently in patients killed in accidents as in those suffering long debilitating illnesses. Table II gives the data for the age group, 66 years to 70 years.

The Marinesco bodies are small, homogenous, eosinophilic, droplet-like structures which lie within the nucleus of the cell (Fig. 1). They vary in diameter from $2 \mu$ to $10 \mu$ with an average of $4 \mu$. As many as four distinct Marinesco bodies may be seen within a single nucleus. Their presence does not usually distort or displace other intranuclear structures or the nuclear membrane. However, when the Marinesco bodies are large or numerous they may displace the principal nucleolus to one side. The nucleoplasm of many of these cells is rarefied but this appearance may be artefactual.

Most of the cells in the substantia nigra cells which contained Marinesco bodies possess two nucleoli. The presence of such double nucleolated cells in the

TABLE I

NUMBERS OF MARINESCO BODIES IN SUBSTANTIA NIGRA IN CASES OF PRESENT SERIES

\begin{tabular}{|c|c|c|c|c|c|}
\hline Age Group & $\mathrm{O}=\begin{array}{l}\text { No Marinesco } \\
\text { bodies }\end{array}$ & \multicolumn{2}{|c|}{$0=\begin{array}{l}1-5 \text { Marinesco } \\
\text { bodies }\end{array}$} & $\begin{array}{l}O=\text { bodies } \\
\text { borinesco }\end{array}$ & $Q=\begin{array}{c}\text { Over } 10 \text { Marinesco } \\
\text { bodies }\end{array}$ \\
\hline $0-5$ & \multicolumn{5}{|c|}{0000000000000000} \\
\hline $6-10$ & \multicolumn{5}{|l|}{000} \\
\hline $11-15$ & \multicolumn{5}{|l|}{ OO } \\
\hline $16-20$ & \multicolumn{5}{|l|}{00000} \\
\hline $21-25$ & \multicolumn{5}{|c|}{ ๑ } \\
\hline $26-30$ & \multicolumn{5}{|c|}{000} \\
\hline $31-35$ & OO & & ○०० & $\odot$ & \\
\hline $36-40$ & \multicolumn{5}{|c|}{ ००००००० } \\
\hline $41-46$ & OO & & 000 & & \\
\hline $46-50$ & \multicolumn{3}{|c|}{0000000} & 0 & \\
\hline $51-55$ & \multicolumn{3}{|r|}{ ๑००० } & 00 & \\
\hline $56-60$ & \multicolumn{3}{|c|}{ ০০০০০০০০০০ } & 00 & 0000 \\
\hline $61-65$ & \multicolumn{3}{|c|}{ ๑००००००० } & 000 & 0000 \\
\hline $66-70$ & 0 & \multicolumn{2}{|c|}{ 0०००००० } & 0000000 & 000 \\
\hline $71-75$ & O & ๑००० & ๑० & 000 & 00000 \\
\hline $76-80$ & & ○० & ○० & $\infty 00$ & $\infty$ \\
\hline $81-85$ & & 000 & 000 & $\infty$ & $\bullet$ \\
\hline $86-90$ & 0 & & & 0 & $\infty$ \\
\hline $91-95$ & 0 & (๑) & & & 000 \\
\hline
\end{tabular}


TABLE II

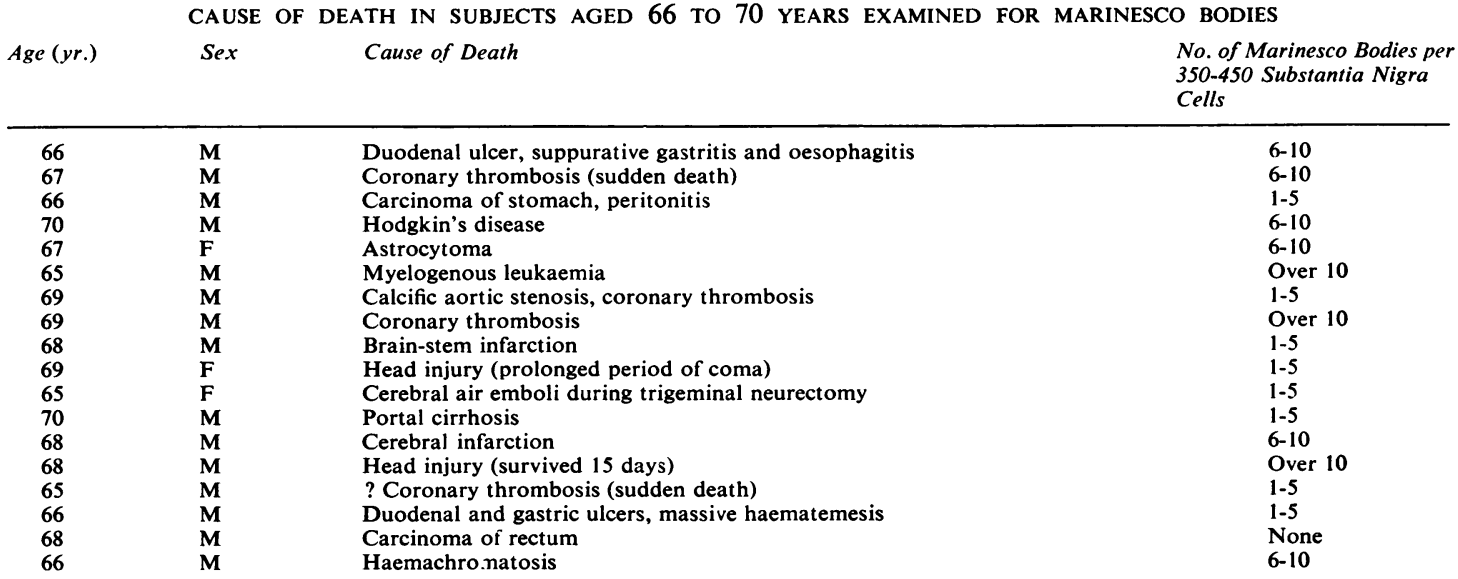
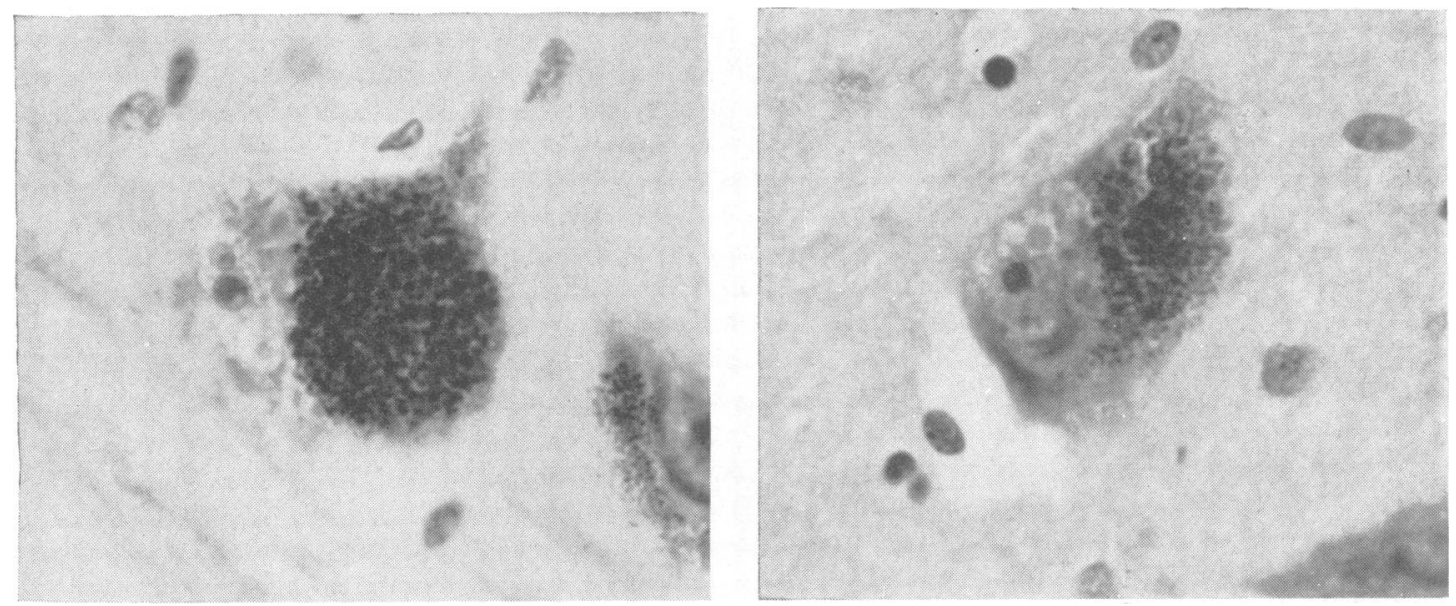

FIG. 1. Typical Marinesco bodies within the nuclei of substantia nigra cells. $\times 256$.

nucleus substantia nigra is neither uncommon nor abnormal. These double nucleoli are always dissimilar in size, the smaller being one-quarter to onethird the size of the larger. The smaller nucleolus can readily be distinguished from the Marinesco bodies by its basophilia and the presence of one or more nucleolar vacuoles (Fig. 2). The Marinesco bodies commonly lie in association with, and appear to be derived from, the nucleoli. This is particularly true of the smaller nucleolus. Two Marinesco bodies, equal or unequal in size, are often found lying on either side of the smaller nucleolus (Fig. 3). In other cells the smaller nucleolus appears to form a basophilic centre of a Marinesco body (Fig. 4). Many of the smaller nucleoli which appear to be giving rise to Marinesco bodies show morphological changes in the form of

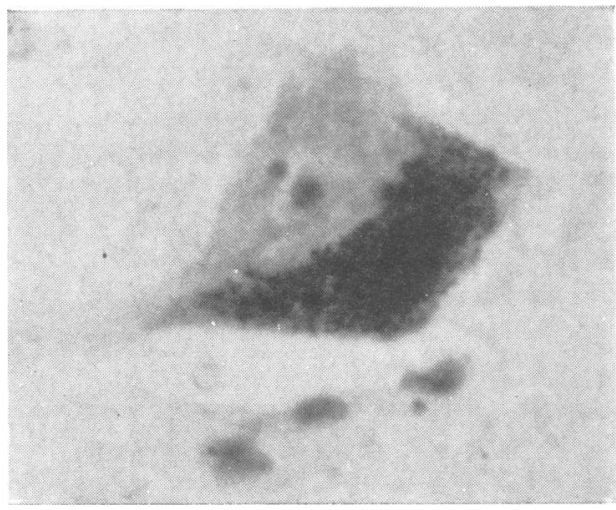

FIG. 2. Substantia nigra cell containing two nucleoli. No Marinesco bodies are seen. $\times 256$. 

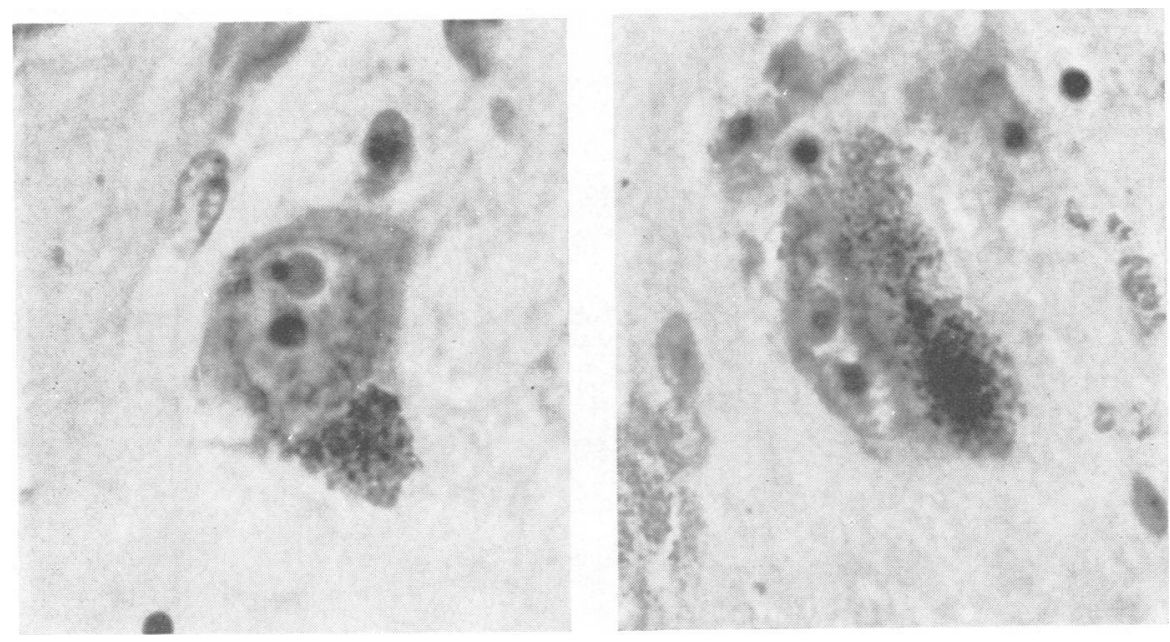

FIG. 3. Cells from the substantia nigra showing the close relationship which Marinesco bodies often bear to the secondary nucleolus. $\times 256$.

FIG. 4. Cell from substantia nigra

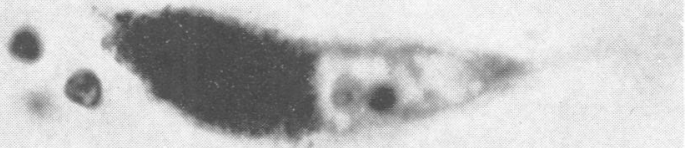
in which the secondary nucleolus forms the basophilic centre of a Marinesco body. $\times 256$
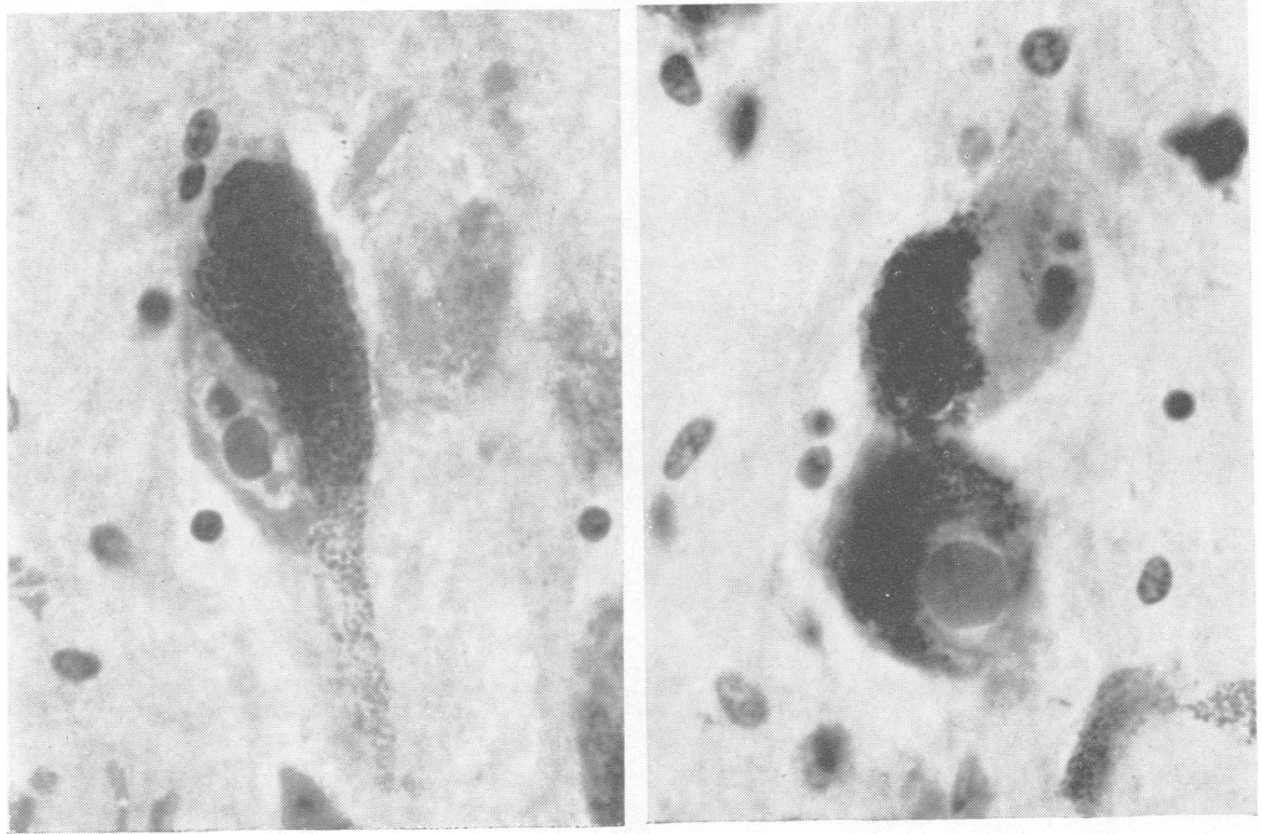

FIG. 5.

Cells from substantia

nigra

containing unusually large single Marinesco bodies. $\times 256$. 
TABLE III

STAINING PROPERTIES OF MARINESCO BODIES

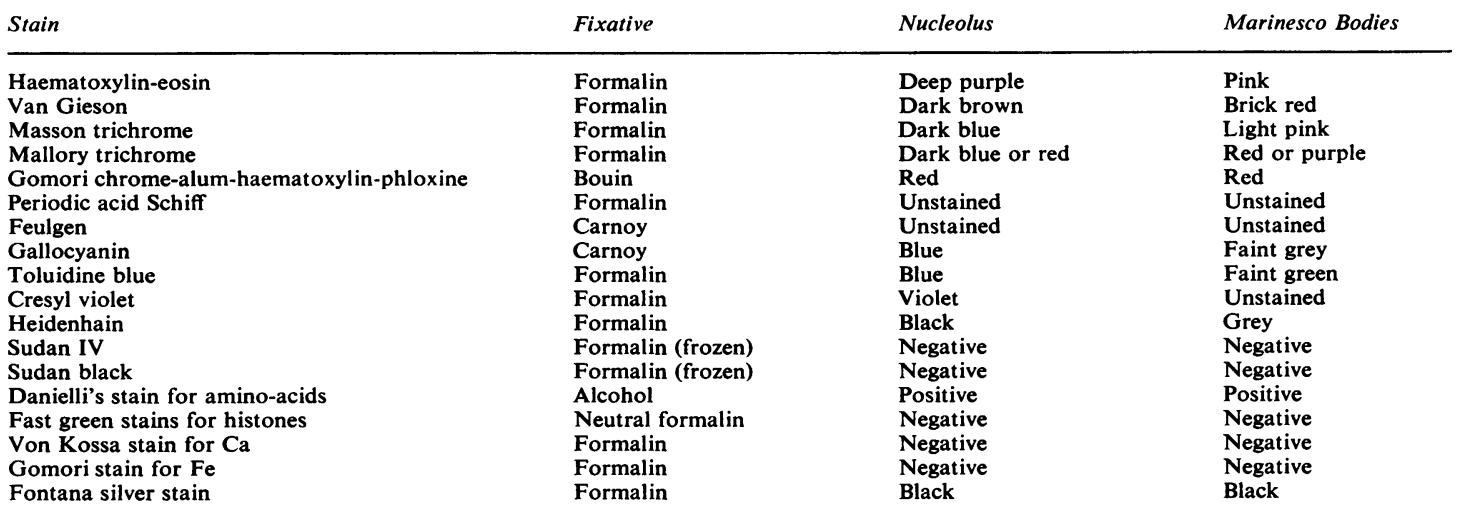

hypertrophy, hyperchromatism, or vacuolization. Vacuolization may progress to the point where only a ghost-like remnant of the smaller nucleolus can be identified. Occasional cells are seen in which the nucleus contains a single, large nucleolus and one or more Marinesco bodies, which usually lie free and rarely in close association with the nucleolus. The foregoing observations have led us to suspect that the free Marinesco bodies of such cells have been derived from a secondary nucleolus which has either not been included on the tissue section or has degenerated to a degree that it cannot be identified. We do not, of course, exclude the possibility that Marinesco bodies may occasionally be found in cells with a single nucleolus.

There was no correlation between the presence of Marinesco bodies and the presence or degree of melanin pigmentation. Melanin accumulates rapidly in the cells of the substantia nigra between the age of 2 and 20 years and no Marinesco bodies could be demonstrated in patients of this age group. The cells of older patients containing Marinesco bodies showed a normal degree of pigmentation. Occasional cells which contain little or no melanin are normally found in the adult substantia nigra. Several such cells with Marinesco bodies in their nuclei were seen. Marinesco bodies were not seen in the cytoplasm of cells of the substantia nigra or in any extracellular location.

The brain-stems of two patients with paralysis agitans were examined. In each case, both intranuclear Marinesco bodies and intracytoplasmic Lewy bodies were demonstrated in cells of the substantia nigra. The Marinesco bodies were no more numerous or larger in these cases than those found in patients of comparable age not suffering from Parkinson's disease. Incidentally, Lewy bodies were not demonstrated in any of the remaining 158 patients.
Marinesco bodies could also be demonstrated in the cells of the nucleus locus caeruleus. There they were much more difficult to find than in the substantia nigra of the same brain-stem. This may, however, only be a reflection of the relative ease with which the two nuclei can be examined.

The staining properties of the Marinesco bodies are detailed in Table III.

\section{DISCUSSION}

The presence of intranuclear or cytoplasmic inclusion bodies is usually considered to be of pathological significance. They are known, for example, to appear in association with many viral infections. Electron microscopic studies have shown that the inclusion bodies in cells infected by certain viruses, such as vaccinia and influenza, are formed by aggregates of virus particles. Such inclusions can also be shown to contain nucleoproteins (Bethlem, 1961). On the other hand, there is considerable evidence that inclusion bodies are not necessarily associated with virus infections. It is well known that inclusions can be induced in the cells of certain tissues by exposure to a variety of chemicals (Wolman, 1954), including lead, bismuth, aluminium, and colchicine. Such inclusions are presumably formed as a consequence of abnormal metabolic activity in the affected cells. Even the inclusions of some known virus infections may reflect abnormal cellular metabolic activity. Bethlem (1961) cites evidence that the Negri bodies of rabies can neither be shown to contain virus particles by electron microscopy nor nucleoproteins by histochemical techniques. Considerable doubt has also been cast on the significance of a positive Feulgen reaction as evidence that certain inclusions are formed by viral aggregates (Bracken, Beaver, and Randall, 1958). 
Marinesco bodies clearly represent a form of intranuclear inclusion. Our observations suggest that they are not of pathological significance since they are found in the pigmented nerve cells of patients of widely varying age who died of a variety of disease processes. These facts would argue against the association of Marinesco bodies with virus disease or exogenous toxins. It is possible that Marinesco bodies reflect an aging or involutional change in the pigmented neurones. If so, it is difficult to understand why they are not found with equal ease in neurones elsewhere in the nervous system. We have not seen typical Marinesco bodies in any cells except those of the substantia nigra and locus caeruleus. It must be admitted, however, that we have not searched any other nuclear groups as diligently. Further, one or two of the illustrations in Wolf and Orton's paper (1932) do suggest that Marinesco bodies may be seen occasionally in nonpigmented cells. If this proves to be true, and if Marinesco bodies do reflect an involutional change, the implication follows that the melanin-pigmented cells may have a shorter life span than cells which are free of this pigment. The fact that the degree of cell loss in the substantia nigra often seems out of proportion to the cell loss in other brain-stem nuclei in elderly patients who die of diseases unrelated to the central nervous system offers support for this assumption.

\section{SUMMARY}

Marinesco bodies are small, intranuclear dropletlike structures found within a proportion of cells of the nucleus substantia nigra and the nucleus locus caeruleus of normal adults. Their presence is thought to reflect an involutional change in these cells.

\section{REFERENCES}

Bracken, E. C., Beaver, D. L., and Randall, C. C. (1958). J. Path. Bact., 75, 253.

Bethlem, J. (1961). In Virus Meningo-Encephalitis, Ciba Foundation Study Group No. 7, edited by G. E. W. Wolstenholme and M. P. Cameron, p. 84. Churchill, London.

Greenfield, J. G. (1958). Neuropathology, pp. 8 and 177. Arnold, London.

Lipkin, L. E. (1959). Amer. J. Path., 35, 1117.

Marinesco, G. (1902). C.R. Acad. Sci. (Paris), 135, 1000

_-, (1909). La Cellule Nerveuse, vol. 1, pp. 195-198.

Wolf, A., and Orton, S. T. (1932). Bull. neurol. Inst. N. Y., 2, 194.

Wolman, M. (1954). J. Path. Bact., 68, 159. 